\title{
e-HR
}

\section{Disrupting the monthly pay cycle}

\section{James Herbert}

James Herbert is Founder and CEO at the Hastee Pay, London, UK.

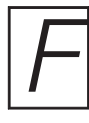

orward-thinking employers

must explore alternative

payment models to stay

relevant in the wake of evolving

demands from the modern workforce.

Employers are continually challenged to go the extra mile in providing workplace perks. This helps

businesses compete by attracting, retaining and motivating talent to maintain healthy levels of productivity in the workforce. Remote working schemes and free food and drink are increasingly common workplace benefits, but are these enough to satisfy the younger generations who will soon make up the majority of the workforce? Employers must fulfil their duty of care, but with millennials and now centennials known to be increasingly expecting workplace initiatives that are flexible, transparent, fast and mobile, employers could find that their duty of care has to extend to covering employee well-being beyond working hours. This is true of all work environments including within the growing gig economy.

The implementation of carefully formulated well-being strategies in the UK workplaces was recently reported to have grown by 20 per cent within the past year, according to REBA's 2017 Employee Wellbeing Research, and that trend looks likely to continue to grow throughout the coming years.

But why should employers care, and how far should the duty of care extend? Some might argue that providing paid employment with fair workplace policies and a comfortable working environment should be enough to keep workforces satisfied. Ultimately it comes down to how much the employer wants to keep up with the evolution of workplace trends and see the correlation to help them attract, retain and motivate the best talent and demonstrate greater levels of productivity.

Although some employers will be content with simply following the best practice trends as they emerge, others will want to be seen as the leaders at the forefront, driving new trends in employee well-being and employee satisfaction. For those that wish to be known as the leaders of the charge, it will be crucial to recognise the most pertinent daily struggles of their employees and explore proactive and practical ways to help provide some form of relief.

\section{Following the money}

By extending their duty of care to cover the financial well-being of the workforce, employers can increase their appeal to new talent, retain existing personnel and ensure the best possible engagement from their workforce. Research from debt charity Step Change shows that financial troubles have a significant impact on mental health with 5,000 users of the charity's online debt counselling service over one year showing signs of anxiety or depression.

The charity's research also uncovered more worrying findings, showing a steep 34 per cent rise in the number of under-25's seeking help with high cost credit in the past 
two years. With experts at Manpower Group predicting that by 2020 millennials (now aged 21-35) and Gen Z (aged 20 and younger) will make up more than half of the entire workforce, the financial well-being of employees has never been a more important factor.

\section{Disrupting the payroll cycle}

Money is undisputedly the number one concern and driver on the minds of most employees. A study done by the American Psychological

Association shows that 61 per cent of respondents face poor mental health because of financial stress. Although free drinks and a nice working environment can improve our work life experience (and a little PR), for most people, money is understandably the reason to get out of bed in the morning.

However, the rising epidemic of financial insecurity has led to a reliance on risky payday lenders, with one in every ten UK employees using payday loans every year and 70 per cent of those relying on payday loans on a regular basis according to research by the Guardian and Pews. And that is before you take into account overdraft fees and the even more worrying and costly alternatives. Employers that can offer a safer, easier and more ethical solution built around those principles will find it easier to recruit, retain and engage talent. By offering an alternative to payday loans, employers can encourage and reward productive behaviour, creating a positive multiplier effect for all parties to win; workers feel less stressed, resulting in greater productivity for employers. Although many could be left scratching their heads over how this can be achieved, the answer is plain and simple. It is time to disrupt the way people are paid.

Although monthly payroll works for the employer, it does not always serve the worker. Beyond the demanding expectations and requirement for instant gratification within younger generations, employers must acknowledge the financial burdens that can so quickly intensify, even for the steady earners. Research from The Times shows that, at a time when both consumer debt and the cost of living are high, and real wages and savings are down, 33 per cent of middle-class families are struggling to pay the bills and could not cope with an unexpected $£ 500$ bill.

Employers still wondering why any responsibility should fall on them should take note that 38 per cent of workers would move to a company that prioritises financial well-being within its workforce according to research by Barclays. Those that use full-time workforces and those that rely on shift, variable, gig and seasonal workers could see huge benefits from offering workers quicker and easier access to their pay. It has also been shown that there is a direct link between effort and reward that benefits both employer and worker.

Removing the struggle of individuals waiting long periods for pay that they have already earned no longer has to rely on businesses changing their payroll cycles and risking cash flow dilemmas. With new HR technologies available, businesses can embrace giving workers instant access to the wages that they have already earned with zero impact on companies' cash flow.

All of the evidence in favour of disrupting existing pay-cycles is there in plain sight, but it is down to employers to decide whether they want to adapt to the necessary demands of the modern workforce or sit back and watch as other businesses take strategic advantage and flourish through a stronger, happier and healthier workforce. I cannot help but suspect that within a few years, we will look back and laugh when reminiscing on monthly pay the same as we do with CDs, Blockbuster video rentals and landline phones. 